\title{
La estética modal como herramienta de análisis cinematográfico
}

\author{
Jesús Ramé López \\ UNED Y URJC, España
}

\begin{abstract}
Modal aesthetics emerges from Nicolai Hartmann's ontology, whose modal distribution has three fundamental categories: the Repertorial, the Dispossitional and the Landscape which diverse dynamic equilibriums articulate both the artwork and the aesthetic experience. In this way, movies and our responses to them would appear as manifestations of diverse "modes of relation", which organize the cinematographic work along with the sensitivities coupling with it, while integrating them both within the technological-historical development.

As a result of the different modal equilibriums available, film poetics can eventually be better understood in their dependence to repertorial aesthetics. Such is the case with classic American which following the logics of the mode of the necessary, has been able to produce and consolidate a series of aesthetic patterns based on invisibility and that have come to us as a collection of filmic forms. On the other hand, the dispositional aesthetics deploy the mode of the possible. This is the case of the film vanguards, where new ways of doing things are built against what was previously considered necessary. Other film aesthetics can put the focus on the mode of effectiveness: this could be the proper focus to understand the character of werewolf, whose iconography comes to a full crystallization in the cinema, while being the object of dispute between a number of differente efectivities that are happening and that change both the man and the werewolf that emerges from the metamorphoses.

Of course nothing here happens in isolation, since modal aesthetics categories are dynamic devices which describe different modal tensions and processes.
\end{abstract}

Keywords: Modal Aesthetics, Modes of Relation, Cinema Teory, Film Analysis and Art

\section{Introducción}

Esta investigación surge de una reflexión sobre la idea del cine como un espacio artístico relacional, donde la importancia la tienen no las imágenes y los sonidos en sí, sino las complejas relaciones que se dan entre ellas. El cine, en consecuencia, debía tener, como la arquitectura para Christopher Alexander, una suerte de lenguaje patrones (Alexander 1980) que puestos en relación harían emerger la obra global. De este modo llegamos a las unidades tonales emocionales de Lukács, que combinadas con la estética para el cine que tenía filósofo húngaro, nos permitía abarcar con una mirada nueva el análisis fílmico. En palabras de Hegel, se daba al cine el carácter de complejidad de complejidades, permitiendo abarcar coyunturas fílmicas de la importancia, por ejemplo, de los gestos actorales —el beso como sello del amor romántico-, o la multitud de formas de relación que se dan en el proceso de montaje.

En este punto dimos con un planteamiento que aunaba todas nuestras inquietudes de análisis, ya que leímos la obra que Jordi Claramonte dedica al estudio del arte y la sensibilidad, y que hasta ahora culmina con su obra Estética modal (Clarmonte 2016). Para una mayor comprensión de la fertilidad del desarrollo de la reflexión de Claramonte, el lector debe entender dos estrategias intelectuales que convergen en esta forma de entender la estética: por un lado la puesta en valor de la ontología modal de Hartmann y por otro la estética relacional de Lukács. Además debemos especificar que el despliegue que hace Claramonte de la estética modal lo hace para el arte en general. En nuestra investigación tras definir estos planteamientos teóricos de la estética modal, pasamos a la aplicación de estos al medio homogéneo propio del cine, para, a continuación, poner en juego estas herramientas de análisis en casos concretos del estudio fílmico. Así, llegamos a analizar, desde las herramientas del pensamiento modal, los estilos de realización y montaje, los géneros, las vanguardias históricas o la confección de arquetipos como el hombre lobo, que construyen su iconografía desde el cine.

Como la estética modal parte de la ontología de Hartmann, esta pone en juego un esquema modal que tiene como categorías fundamentales lo repertorial, lo disposicional y el contexto-paisaje en el que se da la experiencia estética. De esta forma, el cine se vería como un modo de relación, donde lo importante, desde los planteamientos de Lukács, no es solo la obra cinematográfica o la sensibilidad fílmica humana, sino tener en cuenta estos aspectos y sumarlos a cómo funcionan dentro del desarrollo tecnológico-histórico-político. Las poéticas fílmicas pueden acercarse en unos casos a estéticas repertoriales. El cine clásico americano, desde el modo de la necesidad, fue decantando una serie de patrones estéticos basados en la invisibilidad. Las estéticas disposicionales despliegan el modo de lo posible. Es el caso de las vanguardias fímicas, donde los nuevos modos de hacer se construyen a la contra de lo que antes se consideraba necesario. Otras estéticas cinematográficas pueden poner el foco sobre el modo de la efectividad. El hombre-lobo, cuya iconografía cristaliza en el cine, está atrapado en una suerte de efectividades que se van sucediendo en la concatenación de metamorfosis. Aunque hay que pensar que estás poéticas se dan en un una tensión modal, no estáticamente, de tal forma que los modos no emergen de forma pura, estos van cambiando su modulación con el desarrollo de las obras.

En época de desorientación, las herramientas modales nos pueden dar la clave para una análisis en proceso de los modos de relación cinematográficos. En este sentido, debemos entender que lo que 
analizaremos en estas páginas es el cine como arte, dejando de lado el audiovisual como medio de comunicación, haciendo hincapié sobre obras que suspenden su interés y no se vuelcan en funciones mercantiles, como la publicidad, o en las nuevas afectividades que está provocando en las redes a través de la imagen en movimiento.

\section{Hartmann: Ontología modal para el arte}

En la antigua Grecia, con la intención de rebatir los planteamientos hegemónicos de Platón y Aristóteles, en Megara surge una escuela filosófica que pretende enmendar la plana a la teoría de la potencia y el acto como elementos del paradigma ontológico dualista. La dualidad aristotélica no contemplaba lo más importante de su investigación, que no era otra cosa que lo que había entre estos dos momentos del tercero excluido, es decir, el proceso. Nicolai Hartmann recupera en su obra, en concreto en la Ontología (1956), esta olvidada corriente de pensamiento, dando valor al entre que se produce en el curso de las metamorfosis y al tercero incluido. Hartmann desarrolla los modos de su ontología por pares, por un lado la necesidad y la contingencia, por otro la posibilidad y la imposibilidad, y finalmente lo efectivo y lo inefectivo. Este planteamiento es lo que desarrollará claramonte con sus categorías de repertorio, disposiciones y paisaje-complexo. "El modo de lo necesario alude a aquello que tenemos que hacer, el de lo posible a aquello que podemos hacer y el de lo efectivo a lo que de hecho hacemos..." (Claramonte 2016, p. 29)

La categoría modal de lo repertorial se conforma con el modo de la necesidad y su modo negativo de la contingencia. Lo necesario es lo que es así y no puede ser de otra manera, con lo cual el ser contingente sería aquel que no es necesario. Para Hartman el modo de la contingencia, a priori, es el más negativo, aunque de la misma forma es el que tiene un mayor grado de determinación. No debemos confundir el modo de la contingencia con el modo de la inefectividad, que sería lo que no cristaliza ontológicamente, no lo que no es necesario. La contingencia sería un modo a medias, un "modo discutible" (Hartmann 1956, p. 40), pero que tiene una conexión directa con la efectividad. "Lo contingente significaría algo efectivo de lo que se niega tan sólo el ser necesario" (Hartmann 1956, p. 41).

Si hablamos de la categoría de lo disposicional nos encontraremos con los modos de lo posible y su negativo lo imposible que remite a cómo emerge una práctica y a lo que se hace practicable y lo que no. Para definir lo posible podríamos preguntarnos por qué es lo imposible, desembocando en una doble negación, que, en términos estéticos, sería lo que no invalida la cristalización artística, lo que, en definitiva, la hace practicable. Es interesante destacar de cara a la estética que, en ocasiones, también se confunde lo posible con lo efectivo, de tal forma que nos sentimos maravillados con lo que la técnica podría hacer practicable, como si por ser posible tuviera que ser efectivo, pero no prestamos atención a lo que verdaderamente se da en el paisaje-complexo.
Como escribe Brecht en un texto sobre la aparición de la radio, nos dejamos entusiasmar por la posibilidad de que esté "al alcance del mundo entero un vals vienés...", "...nos dejamos dar en las narices por las posibilidades" (Brecht, 1973, p. 5).

Para acabar con la faceta de hacerse cargo de las prácticas del ser humano, los modos de hacer se cristalizarán en la categoría de paisaje-complexo. "Dentro de esta categoría aparecerían los modos de lo efectivo y de lo inefectivo, que son esas cristalizaciones que al final equilibran lo que se va decantando como lo que finalmente emerge" (Palazón y Ramé 2018, p. 769) y lo que no, de tal forma que "la inefectividad se revelara como una impotencia en el paisaje" (Claramonte 2016, p. 108), señalará lo que no ha sido y lo que ha dejado de ser en una dialéctica dinámica. Como hemos advertido anteriormente, los modos no se dan de forma estática sino en transformación, estos se deben entender tal atractores que provocan una tensión cambiante y en diferente modulación.

\section{Lukács: estética relacional para el cine}

Desde el pensamiento modal, el cine puede abarcarse como un arte relacional, donde la experiencia artística se hace compleja, lo cual hace que haya que fijarse en varios factores que la afectan. Así llegamos a la importancia de la perspectiva lukacsiana para la estética, ya que el filósofo húngaro aporta la idea de la experiencia estética como modo de relación donde no solo tiene valor la obra artística, sino que entra en juego la sensibilidad del ser humano, sin olvidar que estos dos aspectos del arte tienen que completarse con el valor que imprime la sociedad en el despliegue de la prácticas creativas, factor, este último, que se olvida en muchas investigaciones sobre el cine, las cuales no han tenido en cuenta la ontología del ser social lukacsiana. Lukács siempre insistió en que no se interpretara el cine sin tener en cuenta su indefectible unión al desarrollo del capitalismo y de las innovaciones tecnológicas, hecho que, en muchas ocasiones, empaña el carácter artísticos de las obras fílmicas porque sus funciones se acercan a las de la mera mercancía. En la sociedad del espectáculo las películas se transforman objetos de consumo: "tal es la utilidad de la mercancía que se basta a sí misma; tal es, para el consumidor, la efusión religiosa hacia la libertad soberana de la mercancía" (Debord, 2008, p. 68). Al mismo tiempo la fascinación por la técnica no debe sustituir al carácter estético, ya que podría dar pie en el estudioso y el espectador al "hábito de considerar, sin ninguna crítica, que cualquier innovación cultural es indudablemente progresista y revolucionaria" (Lukács, 2003, p. 66). Lukács defiende el cine como una nueva belleza y, por tanto, como un nuevo arte, una nueva forma de ver el mundo que tiene un carácter democrático en cuanto al espectador, con lo que estando "predestinado a ser típicamente popular se hunde constantemente en lo meramente agradable, y hasta en lo chapucero y cursi" (Lukács 1967, Vol. IV, p. 207) El filósofo húngaro ve necesario un despliegue más completo de sus posibilidades artísticas, donde 
el cine acerque el arte en su reflejo fotográfico desde lo que nos rodea, promoviendo que "lo vivo de la naturaleza reciba forma artística: el murmullo del agua, el viento entre los árboles, el silencio de la puesta de sol y el bramido de una tormenta como procesos naturales se convierten en arte" (Lukács, 1973, p. 73).

Según Lukács el arte es un reflejo antropomorfizador, por que pasa la realidad por el tamiz intelectual del ser humano, así la puesta en escena ordena el mundo para ser rodado. El cine, en su filmación o grabación, tiene una base tecnológica, ya que necesita un dispositivo que registre las imágenes en movimiento, esto respondería a un reflejo científico-técnico, es decir, un reflejo desantropomorfizador, que recoge las imágenes de forma mecánica. Esto provoca que el cine pueda tener un carácter científico cuando grabamos y luego aceleramos el movimiento, por ejemplo, del crecimiento de una planta; al mismo tiempo, dicha imagen acelerada, puede generar una experiencia estética, una poética de la vida. Para que esta imagen en movimiento pueda tener aspiraciones artísticas necesita de la técnica fílmica, siendo esto lo que compone lo que Lukács define como el medio homogéneo del cine, su peculiaridad como arte, su mímesis singular. El montaje propone una nueva dimensión antropomorfizadorra, en un nuevo reflejo reantropomorfizador, el cual desarrolla la mímesis estética necesaria para reconocer el cine como arte.

Lukács despliega diferentes categorías que complementan este planteamiento tan fértil para el análisis fílmico. La más destacable es la idea de unidad tonal emocional, que es lo que se da en el cine como experiencia estética, "es una clave de sensibilidad, un orden de atención específico que impregna y abraza todos los elementos del film: la narrativa, la fotografía, la música..." (Ramé y Claramonte 2019, p. 287). Esta tonalidad total se compone de pequeñas unidades tonales que van sucediéndose y enlazándose, como si fuera una cadena creada de eslabones, recogiendo esta metáfora, por parte de Lukács, de Lenin. Así el medio homogéneo se compondría en esta unidad tonal emocional total, que al mismo tiempo como complejidad de complejidades hegelianas, tiene diferentes unidades tonales que se ponen en relación. Claramonte afina más y las llama unidades tonales experienciales, para introducir en la experiencia estética no solo elementos emocionales.

\section{Estética modal como herramienta de análisis fílmico}

Lo interesante del planteamiento de la estética modal de Claramonte es que hace hincapié en las relaciones intermodales, apelando al dinamismo de la realidad y en concreto de las experiencias estéticas, donde "todo modo de relación aparecía entonces como la articulación de un repertorio con unas disposiciones situadas conflictivamente en un paisaje" (Claramonte 2016, 27). Así, tendríamos una atención por lo artístico si atendemos a lo repertorial, si nos concentramos en los medios homogéneos, que en el cine responde a esa mímesis estética que implica un manejo del material fílmico para el visionado, una reantropomorfización, desde el montaje, ya sea entre imágenes en movimiento, internamente en desarrollo del plano o entre imágenes y sonidos. El lenguaje clásico cinematográfico ha decantado un repertorio de formas artísticas y modos de hacer que ha servido para crear reglas de producción que, por ejemplo, se basan en la invisibilidad del montaje y en la estructura narrativa clásica de los tres actos. El cine clásico, tras el paso al sonoro, desarrolló lo que podríamos denominar, en palabras de claramonte, un canon efectivo, el cual nos da cuenta de la potencia expresiva dentro de un lenguaje de patrones o de una unidad total experiencial. El lenguaje clásico fílmico ha servido como conjunto de formas que ponían en juego distintas expresiones de nuestra potencia artística, pero "no todo canon puede reclamar idéntica potencia repertorial y ese será un factor de evaluación crítica que el pensamiento modal hará posible" (Claramonte 2016, p. 217). Una estética repertorial es una poética de lo necesario, por lo tanto ya no estamos en el todo vale, sino en el intento de apreciar el valor artístico del cine. El cine debe partir de esa idea nietzscheana de ser para el conjunto y para nadie, de ser un procomún. Recuperamos la idea de un cine para la vida, en el sentido lukacsiano, donde el ser humano entero de la cotidianidad, se convierte en ser humano enteramente en una experiencia estética fílmica, un momento perteneciente a todas las personas y de nadie, dándonos una herramienta común que nos hace volver a ser seres humanos enteros, pero cambiados, enriquecidos y más armados para hacernos cargo de nuestra vida.

El western como género, por ejemplo, desarrolla un triángulo repertorial que le permite expresar todos aspectos que inquietan al ser humano, existiendo un "película de vaqueros" para cada tema social. Parte, como explica Claramonte (2015), de cómo en Europa los cercamientos implicaron que la gente tuviera que emigrar a EE. UU. , ya que estaban desacoplados ante el avance del capitalismo y sus nuevos repertorios. Además, surge un nuevo desacoplamiento que viene dado por el avance del capitalismo en EE. UU., dando como resultado la sepultación de los modos de hacer del estilo de vida del cowboy. "El westman es un elefante instituyente en la instituida cacharrería del naciente capitalismo mercantil y colonial" (Claramonte 2015, p. 29). Sus funciones son principales, secundarias, colaterales e incluso contingentes, de tal forma que hace muy efectivas sus narrativas, permitiendo múltiples lecturas; por eso en algún caso se ha comparado este género con la narrativa mitológica, de la que bebe artísticamente - The Searchers (1956) fue tradicida en España como Centauros del desierto-. El repertorio fílmico que compone el western se define por unos temas que enmarcan su narratividad, otra parte expresiva que define el tono y finalmente un estilo que lo identifica estéticamente, dando lugar a un triángulo repertorial propio. Aparecen dicotomías como vaqueros/Indios, agricultores/ganaderos, a un lado o a otro de la frontera, Progreso/tren o la maquina de vapor/capitalismo industrial. El estilo esta marcado por el espacio geográfico, el vestuario o la música: esto 
ha derivado en estructuras de realización que ahora son clásicas, como el duelo, aparte de aportes a la planificación como el plano americano. Para que el triángulo esté completo se recurre a la épica, el drama o el melodrama para dar el tono propio de este género. Un caso muy claro de este uso repertorial del lenguaje fílmico es la filmografía de John Ford.

Por otro lado, si nos centramos en lo estético, habría que atender a lo disposicional, es decir, a "lo que busca variación, juego y movimiento" (Claramonte 2016 , p. 157). Un caso muy claro son los cambios que se pueden dar en el desarrollo de un género: proceso que sigue, por ejemplo, el surgimiento del spaghetti western, hecho que emerge en un momento de relaboración estética en la decadencia del western. Otro caso similar es el de la adaptación del lenguaje fílmico de este género a películas de ciencia ficción como Blade runner (1982).

Nos vamos a detener en un ejemplo más bizarro para que se entienda este tipo de poéticas cinematográficas con más claridad, analizando lo que hemos denominado neorrealismo kitchs. En todo momento tenemos que entender que estas diferenciaciones se dan en dialéctica entre los modos y las categorías modales, pudiendo analizar, en este caso, la dialéctica que se da, por ejemplo, entre lo disposicinal y lo repertorial, y que podríamos traducir en palabras de Calramonte entre "la praxis y la fábula, la novedad y la confirmación" (Claramonte 2016, p. 157).

Nos referimos con neorrealismo kitchs a un conjunto de películas italianas de serie $B$ que nacen en los 80 , las cuales tienen como propósito imitar a superproducciones de ciencia ficción como Alien: el octavo pasajero (1979), Terminator (1984) o Mad max (1979). Los ejemplos más destacables son: Terminator II. Shoking Dark (1990) de Bruno Mattei y Alien II. Sobre la tierra (1980) de Ciro Ippolito y Biagio Proietti. Analizaremos como emergen esas nuevas formas dentro de un contexto político y de un desarrollo tecnológico concreto. Aquí salen a nuestro encuentro dos categorías fundamentales, por un lado la idea de mímesis en el arte desarrollada por Lukács y Tatarkiewicz (2015), recuperando las reflexiones de los clásicos griegos. En el cine aparecen tres diferentes tipos de mímesis destacables: la puesta en escena, el reflejo mecánico de la grabación y una mímesis estética. A todo esto hay que sumar una idea de imitación muy propia del cine y cuyos mimbres son fáciles de reconocer: duplicación metacinematográfica o cuando lo que se pone en juego es la recuperación de un repertorio artístico, siendo objeto de imitación, hasta el plagio burdo de las obras artísticas directamente. Es lo que se denomina "suecadas", término que viene dado por la película de Michel Gondry Rebobine, por favor (2008) _-Originalmente pirata en algunos países latinoamericanos-. En este film, los protagonistas tienen que rehacer, de forma casera, las películas de su videoclub ante la ruina que se les avecina por el incendio de su establecimiento. Como tardaban mucho en hacerlas, los autores decían que venían de Suecia, de ahí que ahora llamemos a las películas que son copias de otras "suecadas".
El cine siempre ha echado mano de la mímesis, o de la copia y el plagio directamente, para hacer remakes, adaptaciones, Spin off... Exactamente es esto lo que ocurre con las películas del neorrealismo kitchs y sus soluciones miméticas, que se introducen dentro de la siguiente categoría que nos asalta: lo Kitsch. Eco relaciona lo kitsch con el mal gusto, explicando que son tan difíciles de definir como el tiempo para San Agustín o el arte en general para Benedetto Croce, "Todo el mundo sabe lo que es, y nadie teme individualizarlo y predicarlo, pero nadie es capaz de definirlo" (Eco, 2004 , p. 95). Esto provoca que en muchos casos se deje la labor de crítica para los teóricos y los expertos, los cuales a veces, dependiendo del momento histórico y político, descubren atisbos de belleza en películas de serie $\mathrm{B}$, como la filmografía de Jaques Tourne o en géneros desprestigiados como el nombrado spaghetti western. Pero no debemos confundir el mal gusto con lo Kitsch, ya que, por ejemplo, las vanguardias recurren al mal gusto o su crítica para combatir los repertorios estériles y abrir el paisaje a la posibilidad. Es el caso de lo que ocurrió en España con las Conversaciones Cinematográficas de Salamanca a mediado de los años 50, donde Juan Antonio Bardem declaró: "El cine español es políticamente ineficaz, socialmente falso, intelectualmente ínfimo, estéticamente nulo e industrialmente raquítico" (Valverde, 1998). Aquí aparece el modo lo posible para denunciar, en todos los sentidos lukacsianos —Obra, sensibilidad y política-, un repertorio cinematográfico que siendo contingente debe ser renovado. Las películas de Bardem y Berlanga fueron ejemplo de una nueva colección de formas que permitían explicar el franquismo tardío lúcidamente. Las vanguardias, en otras ocasiones, han recurrido al mal gusto no para criticarlo, sino para un enfrentamiento con las normas fílmicas establecidas. Lars von Trier, y el movimiento Dogma 95, investigaron la idea de hacer practicable la perdida del gusto, en contraposición con un gusto impuesto desde la sociedad capitalista. Su planteamiento práctico consistió en un decálogo de normas dejado por escrito, que contraponía los modos de hacer no escritos del cine mainstream. Las vanguardias o movimientos cinematográficos se construyen desde hacer practicable un nuevo repertorio necesario, siendo un ejemplo claro de esto la aparición de los nuevos cines en los años 50 y 60 en Europa y Latinoamérica.

Muchas de las películas que hemos definido como neorrealismo kitchs se basan en films que habian intentado dignificar el género de la ciencia ficción. Una vuelta de tuerca a lo repertorial desde lo disposicional, ya que se imitan películas que se crearon con el fin de hacer más fértil estéticamente un género, pero esta imitación se hace precisamente desde la serie $B$, y banaliza esos valores artísticos que se quisieron resaltar —el film más claramente imitado es Alien-. Eco refiriéndose al mal gusto, que la cultura alemana denomino kitsch, dice que es la "Prefabricación e imposición del efecto" (Eco, 2004, p. 96), definición muy cercana a la espectacularización de Guy Debord o cuando Adorno define al arte controlado por las necesidades del mercado. 
Si nos fijamos en la tradición neorrealista italiana, podemos destacar el uso de espacios naturales, actores no profesionales y cierta precariedad, provocada por el momento histórico del fin de la II Guerra Mundial, en la producción. Estos rasgos se repiten, por motivos puramente mercantilistas, en las producciones de neorrealismo kitchs, aparte de aparecer la ciudad como protagonista. Es el caso de Terminator II. Shoking Dark donde Venecia aparece como la ciudad de Muerte en Venecia (Luchino Visconti, 1971) adaptada a la ciencia ficción. Alien II. Sobre la tierra utiliza el espacio natural de una cueva para su relato fantástico, así vemos que las técnicas y narrativas de este género son utilizadas, pero como recurso mercantil, con el fin de hacer películas más rentables. Los efectos especiales se combinan con el bajo presupuesto, donde lo que en un principio es el esfuerzo de crear un estilo e imaginario tipo Star Wars, se convierte, en un visionado actual, en una patético muestra de falta de recursos. Un elemento común de estas películas es dejar un final abierto para seguir explotando la gallina de los huevos de oro, ya que estas películas, hasta que llego una regulación comercial más dura, se estrenaban en toda Europa como si fueran las segundas partes oficiales de las películas originales. Otros ejemplos son Contaminación alíen invade la tierra (1980) de Luigi Cozzi o 2019, tras la caída de Nueva York (1980) de Segio Martino, esta última mezcla de Parsifal, Mad Max, Star Wars, Terminator, La bella durmiente, Fumanchú y James Bond, todo en un mejunje sobrecargado, pero que recuerda al uso de las referencias culturales en películas como Matrix (1999). De hecho, en la actualidad, películas sagas cinematográficas como Divergente o Los juegos del hambre desarrollan temas ya tratados en el neorrealismo kitchs, incluso la película de Alfonso Cuarón, Hijos de los hombres (2006), esta basada en 2019, tras la caída de Nueva York, al igual que Paul Verhoeven hace con la serie $B$ en sus películas Desafío total (1990) o Starship Troopers (1997), caso similar al de Tarantino con el Spaghetti.

Por todo esto denominamos neorrealismo kitchs a dichos films, pero, trayendo la discusión al presente, si tomáramos estas obras, en palabras de Lukács, como totalidades cerradas en sí y perfectas en sí, o si usáramos la idea de Tomás de Aquino de integritas-consonacia-claritas —también nos valdría la idea del artista y teórico del arte húngaro, György Kepes, de imagen, forma, función y necesidad-, nos daríamos cuenta de que estas películas no funcionan artísticamente porque el efecto se ha hecho el protagonista y el publico ya no perdona "lo falso". Esto nos lleva, desde la estética modal, a reflexionar sobre el cine mainstream actual, y si no estaremos viviendo, en este momento de desorientación Kitsch, una búsqueda continua del efecto que lo pagara con un mal envejecimiento de las obras fílmicas que ocupan los multicines de nuestros barrios.

Queda claro que las estéticas disposicionales no se pueden ensimismar y basar en la creatividad continua del emprendimiento capitalista. Esto no es autonomía artística, ya que la autonomía, desde la estética modal, "solo puede plantearse como un proyecto colectivo, instituyente y contagioso basado en un repertorio potente y cuidado entre todos" (Claramonte 2016, p. 235). De ahí que el cineasta tenga que tener lo que Lukács denomina moral de responsabilidad, es decir, que el artista debe tener en cuenta lo que va a suponer su obra en sus consecuencias colectivas, una combinación de lo repertorial y lo disposicional que genere "gradientes de tensión, patrones de espera y resolución, juegos del hambre y la incertidumbre" (Claramonte 2016, p. 157).

No debemos olvidar que, en otras ocasiones, nos centramos en lo cismundano, estamos pendientes del contexto-paisaje, de lo que implica la efectividad o la inefectividad, dando un nuevo modo de ver al mundo que nos rodea. Las estéticas de la efectividad nos trasladan a un paisaje donde las contradicciones están en un equilibrio tensional. Así aparece una categoría, reivindicada por Merleau-Ponty, muy importante en la estética modal y que nos facilita la explicación: la idea de quiasmo. Este concepto "permite poner en juego la dualidad eludiendo el dualismo" (Claramonte, 2016, p. 250), de tal modo que la contradicción, por ejemplo en una superheroína, entre ser humano entero (vida cotidiana) y ser humano enteramente (vida de poderes puestos en juego) no excluye estos estados, sino que los desdobla en lugar de suprimirlos. A los superhéroes y monstruos que sufren una metamorfosis les "define el modo de relación mediante el que ponen en juego su propio quiasmo" (Ibidem, p. 250).

Claramonte echa mano de los superhéroes y las superheroínas para explicar este concepto, lo que nos permitirá adaptarlo a un caso fílmico concreto, en un intento de explicación de las metamorfosis de los personajes. Si tomamos como ejemplo a Spiderman/ Peter Parker, cuyo cambio en la pantalla lo provoca el traje, lo que nos interesa es el entre, el tiempo en el cual ya no es un simple estudiante, pero tampoco es todavía Spiderman. Ese entre es lo que nos va a interesar para estudiar la metamorfosis del personaje del hombre lobo, que hemos denominado el quiasmo de la fatalidad, ya que al hombre lobo le sucede lo mismo que a Hulk, que no se transforma a voluntad, por lo tanto no domina la modulación de su quiasmo y esta sometido a la fatalidad de ciertos procesos. El licántropo no controla su quiasmo, no controla el momento de la transformación, sus cambios son espontáneos, no son Voluntarios. Hulk depende de su ira y el hombre lobo de la luna.

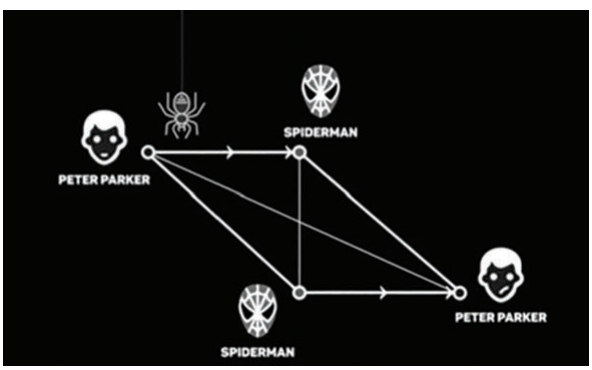

Figura 1 - El quiasmo Spiderman/Peter Parker 
El hombre lobo es un personaje que ha cristalizado a través del cine y que no tiene el origen literario, más haya de la cultura popular oral, en una novela de éxito como otros monstruos clásicos, veasé Drácula o Frankenstein. Así que la secuencia estrella de las películas con hombre lobo, la transformación, se ha forjado como un imaginario propiamente cinematográfico. La metamorfosis cinematográfica de ser humano a hombre lobo nos recuerda al juego lukacsiano del paso de ser humano entero a ser humano enteramente, el hombre pasa a ser hombre lobo, pero cuando vuelve a ser hombre ya no es el mismo hombre, de la misma forma que cuando vuelve a transformarse en hombre lobo también ha influido lo vivido como hombre. En un repaso de las películas de hombres lobo, nos damos cuenta de que en lo efectivo de cada una de ellas se pone énfasis en algún aspecto del repertorio popular de la licantropía. En las sagas cinamatográficas de Crepúsculo basadas en libros homónimos de Stephenie Meyer o Underworld, por ejemplo, se explota la batalla entre licántropos y vampiros.

Vamos a comparar dos obras concretas para entender cual son los temas en los que se centran, pese a contar la misma historia, y qué se desprende de sus propuestas fílmicas: El hombre lobo (1941) de George Waggner y su remake El hombre lobo (2010) de Joe johston. La primera se centra en la posibilidad de que cualquiera puede ser convertido en hombre lobo, como pesadilla no resuelta, quedando muy claro en un poema que recitan varios personajes a lo largo del film: "Incluso un hombre que es puro de corazón y pide gracias en cada oración; Puede convertirse en un lobo, cuando es atacado en un bello campo durante la luna brillante de otoño".

El remake de 2010 hace hincapié en un hecho moral de la transformación, al plantear que es más fácil matar a la bestia, al hombre lobo, que al hombre, hecho que se refleja en la siguiente frase pronunciada en el film y que expresa el quiasmo que se pone en juego: "Dicen que matar a una bestia no es pecado, sólo si se hace a un hombre, pero donde está el límite entre la bestia y el hombre". También existe diferencia en estas dos películas en lo que Aristóteles definía como la anagnórisis, ese momento del reconocimiento. Este gesto se da en el cine cuando reconocemos que el monstruo ha muerto, pero aparece el ser humano que ocultaba, consecuencia de que las heridas provocadas al hombre lobo se reconozcan en el hombre. En la película de 1941, la anagnórisis se da por el espectador cuando el cíngaro es reconocido como el lobo muerto por el protagonista ante su ataque. Sin embargo, el remake de 2010 da agnición desde el punto de vista de la protagonista, cuando esta reconoce en el hombre lobo muerto a su amado. La metamorfosis de hombre en hombre lobo refleja la teoría de diamantes que incorpora la estética modal para explicar el arte como modo de relación. Diamantizar, desde los planteamientos de Rudolph Kaehr, "supone abstraer y subvertir el nivel semántico de tematización para así poner en primer plano los patrones, los morfogramas de interacción o reflexión de la comunicación" (Claramonte 2016, p. 160). De este modo para construir un diamante, en una suerte de geometría oposicional, colocaríamos una proposición en uno de sus vértices y en el opuesto la proposición contraria, en los vértices que quedan colocaríamos la posibilidad de que la dos se den a la vez y la de que no se den ninguna de las dos.

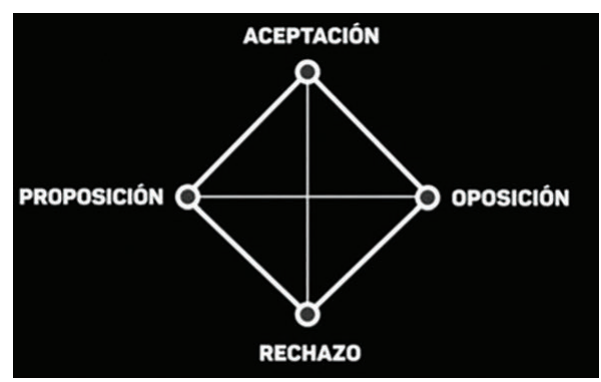

Figura 2 - Esquema del diamante de Kaehr

El uso de esta herramienta epistemológica abre la reflexión y te permite ser preciso con el análisis de los procesos, de hecho, en nuestro caso de la metamorfosis del hombre lobo podríamos organiza para organizar diferentes aspectos de dicha transformación. Nosotros colocaremos en vértices opuestos al hombre antes de la transformación y al hombre después de la transformación, de tal forma que nos quedan por analizar los entres que se dan progresivamente del hombre en sus metamorfosis en bestia. No podemos detenernos mucho, pero por ejemplo nos iremos dando cuenta de que la el hombre no es el mismo cada vez que vuelve de su transformación, pero la bestia tampoco, con lo cual podemos ver en el transcurso de las películas como el proceso de transformación hace que cada de cada nuevo cambio emerja una nueva criatura, de la misma forma que se influyen mutuamente ser humano entero $\mathrm{y}$ el ser humano enteramente. Pero en el hombre lobo también se desarrollo un tema fundamental para la estética modal, es el hecho comunicativo y el lenguaje. La bestia podría tener, como el animal, un sistema de comunicación, como los aullidos, pero no un lenguaje. El cine ha utilizado mucho la figura retórica de la personificación para hacer hablar a los animales, siendo Disney una productora experta en crear estrellas cinematográficas no humanas, de tal modo que cuando vemos a, como diría Lukács, un ser-animal hablando en pantalla, ssurge una especie de antropomorfización. Esto ocurre en la saga que siguió a El planeta de los simios de Franklin Schaffner (1968), en concreto, en una secuencia de El origen del planeta de los simios de Rupert Wyatt (2011), el simio llamado Caesar pronuncia de repente la palabra "No", lo cual da un valor humano a ese simio en concreto frente a sus congéneres. El lenguaje juega un papel dentro de los estereotipos cinematográficos y en el hombre lobo se decanta el repertorio del personaje por la ausencia de lenguaje, su mudez le hace perder 
humanidad. Esto provoca que cuando se ha jugado con el género de terror desde la disposicionalidad, el hombre lobo habla generando en la mayoría de los casos giros humorísticos.

El arquetipo es tan fuerte que en todo este estudio hemos hablado de hombre lobo y no de mujer lobo, ya los ejemplos de esta última son escasos, aquí es interesante que destaquemos el carácter situado de las películas que nos reclamaba Lukács, ya que en nuestra sociedad este personaje va a simbolizar la bestialidad sexual masculina, que está presente en casi todas las películas. Los pocos ejemplos de mujeres lobo, como la saga que inaugura Ginger Snaps de John Fawcett (2000), la licantropía se mezcla con el deseo sexual, pero tratada como una enfermedad, no como la fatalidad del hombre lobo, dando pie, por poner un ejemplo, a un estudio de los nuevos personajes femeninos, donde el interrogante es si tienen un carácter emancipatorio o por el contrario siguen favoreciendo las relaciones de poder establecidas. Quizá la clave sea que en el cine aparezcan, desde lo posible, alternativas a los repertorios contingentes para representar la feminidad. Este es otro interrogante que nos ha abierto la perspectiva modal, ya que lo que nos da esta visión estética son direcciones a las que mirar para, de este modo, hacer un análisis complejo del hecho fílmico y no perderse en ensimismamientos personales o respondiendo a intereses fuera del estudio de la realidad artística.

\section{Conclusión}

Después de haber explicado los modos y alguna de las interrelaciones que se dan entre estos en el cine, nos hemos dado cuenta de que cuando más fértil es la estética modal para la teoría fílmica es cuando se explica el recorrido modal entero, cuando se ve el hecho cinematográfico como un modo de relación y no nos preocupamos solo de lo repertorial, lo disposicional o el complexo-paisaje. Esto es lo que le sucede habitualmente a los análisis cinematográficos en general, sin embargo creemos que nuestra reflexión debe responder a la atención a ese camino que va creando efectividades dentro de tensiones que se van acercando dialécticamente hacia los diferentes modos de lo necesario, lo contingente, lo posible y lo imposible. Esto también nos explica porque en algunos casos las películas tienen una gran potencia artística, dándole altura a la obra, provocando una comunidad selecta de gusto, y por otro lado otros films tengan una gran conectividad que da anchura a su propuesta, y así permiten que más personas se acoplen con esta, que más personas sientan que la entienden, al mismo tiempo que, en otras ocasiones, aparece la carencia de estas características.

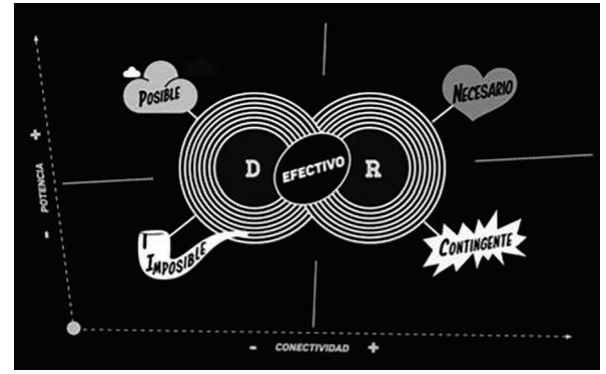

Figura 3 - Esquema modal completo

Si seguimos el esquema modal con un ejemplo que propone Claramonte, podemos ver que los procesos en los cambios artísticos se pueden explicar recuperando la noción de panarquía, dándose cambios desde la destrucción a la reorganización en relación con los diferentes modos de la necesidad, la contingencia, la posibilidad y la imposibilidad. Se identifican "cuatro funciones, las cuatro clases de inteligencias, características de todo ciclo adaptativo podrían ser denominadas con los términos: conservación, liberación, reorganización y explotación" (Claramonte 2016, p. 142).

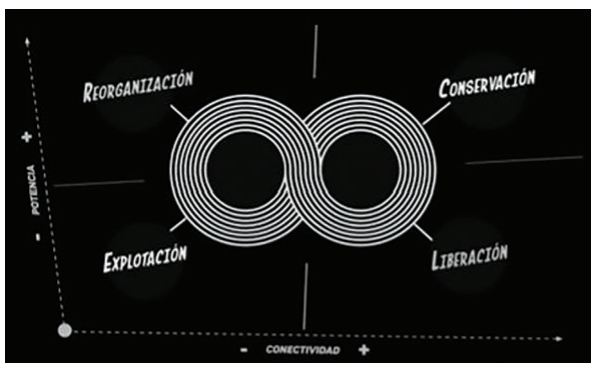

Figura 4 - Esquema modal de la panarquía

Claramonte elige para explicar este proceso panárquico los momentos de la «Vida de las formas» de Focillón, asignando a cada movimiento artístico un modo respectivo: a la necesidad el clásico desde la idea de conservación repertorial, a la contingencia el manierismo en su liberación, a la posibilidad el barroco desde la reorganización y a la imposibilidad el arcaico vinculado a la explotación. Para que se entienda cinematográficamente, hemos elegido, para dar nuestra conclusión, el movimiento artístico del Neorrealismo italiano, el cual surge de las nuevas disposiciones que quieren acabar con un repertorio artístico ya obsoleto. En la época fascista italiana, se decanto un tipo de cine que imitaba al norteamericano, pero que además no tenía relación con la realidad del país, de hecho lo llamaban cine de "teléfonos blancos", ya que estos aparecían en las películas cuando en las casas italianas no existían, reflejo de ese alejamiento de lo que ocurría en Italia y de esa mímesis de las películas de Hollywood. Como escribe 
Ugo Pirro, "la introducción en la escenografía fascista de este objeto que el color blanco hacia irreal y raro, se debió a la admiración secreta, pero difundidísima, que todos tenían por el cine americano" (Pirro 1990, p. 30). Vemos que este repertorio de formas, que habían tenido su función, como el periodo clásico, dejan de ser fértiles y empiezan a ser una repetición de gestos fílmicos, convirtiéndose en una caricatura de sí mismos, una sobreabundancia de previsibilidad, donde, como en el manierismo, su repertorialidad "ha dejado de estar contenida para empezar a volverse un tanto excesiva o cuanto menos irreducible a un único criterio de unidad, como era característico en el momento clásico" (Claramonte 2016, p. 142). Con el fin de la Segunda Guerra Mundial, el cine italiano empieza a experimentar. Como ya hemos mencionado, la precariedad hace que los directores elijan espacios naturales y actores no profesionales, pero al mismo tiempo empiezan también a transformarse las narrativas, más cercanas a las vidas de los italianos medios y al formato documental. Un claro ejemplo de este momento es el largometraje de Vittorio de Sica, El ladrón de bicicletas (1948), donde se experimenta con las nuevas posibilidades de sacar la cámara a la calle y captar la realidad. Esto es lo que nos lleva al momento de reorganización que Claramonte identifica con el barroco y que da paso a la explotación del modo de la imposibilidad, donde se empieza a perder conectividad, lo que provocó en muchos casos que el neorrealismo se hiciera incomprensible, momento que hemos identificado con el periodo arcaico. El resultado fue que los cineastas componentes de la corriente neorrealista italiano sacaron un manifiesto, el cual, en cierto modo, marco el camino repertorial que se iba a decantar después y que definiría a este movimiento fílmico. El neorrealismo logró convertirse también en un repertorio clásico que por imitación en exceso también perdió potencia $\mathrm{y}$, como al manierismo, en muchos casos dejo al movimiento en una caricatura.

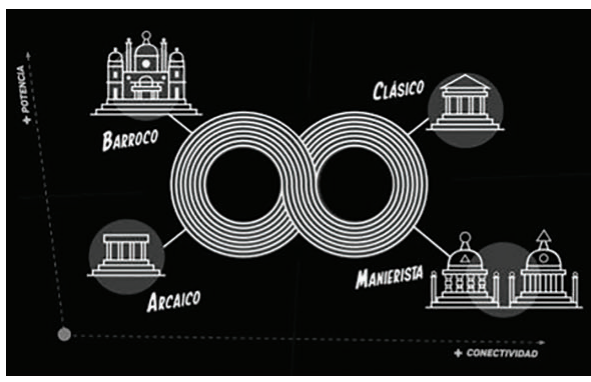

Figura 5 - Esquema modal de los momentos de la «Vida de las formas» de Focillón.

De este modo nos hemos dado cuenta de cómo los repertorios nuevos surgen a la contra de la contingencia de otros y se convierten en el nacimiento de una colección de formas relevantes en sí misma. Así, el guionista italiano Cesare Zavattini en Tesis sobre el neorrealismo escribía: "El neorrealismo es hoy nuestra única bandera" (VV. AA 1993, p. 205).
Pero si nos fijamos en los futuristas vemos que en su manifiesto Cinematógrafo futurista creían que su cine llevaría "a la renovación general, reemplazando a la revista (siempre pedantesca), al drama (siempre previsible) y matando al libro (siempre tedioso y opresivo)" (Ibidem, p. 20). Vertov escribía en Nosotros: nos llamamos "los kinoks para distinguirnos de los cineastas, atajo de chamarileros que apenas logran encubrir sus antigüallas" (Ibidem, p. 37). Otro caso es el de Mario Rodríguez Alemán, en el texto inaugural El movimiento documental en cuba, cuando escribe que "El cine no encontró su camino recto en Cuba hasta después de instalarse la revolución en el poder" (Ibidem, p. 166). Podemos estar incluso en oposición a la idea de arte de estos textos, pero queda claro que estos artistas intentaban buscar un repertorio lúcido que les permitiera hacer fértil al cine como modo de relación artístico, estético y político.

No debemos olvidar que estos estadios se dan en continuo cambio y en muchos casos en simultanedad. Hemos elegido el neorrealismo porque nos parecía un ejemplo claro, pero no un ejemplo paradigmático, ya que cada experiencia estética desarrolla su tensión modal, alejándonos de una idea determinista donde se vayan dando pasos, sino que cada gesto fílmico tiene su equilibrio estético de lo efectivo en continuo cambio. A veces nos sorprendemos de cómo las películas, de forma inconsciente, remiten a los modos y esto nos da a entender que este funcionamiento tiene que ver con formas cinematográficas decantadas. En a película El atraco (2009), tres personajes se siente muy mal con su existencia al saber que el museo en el que trabajan se va a llevar sus obras a Dinamarca, con lo cual dejaran de admirar cada uno una pieza del museo que les acompaña en su quehacer cotidiano. El apego con cada obra de cada personaje, sorprendentemente, recurre a una aproximación al arte desde uno de los modos: Uno de los personajes está tan obsesionado con un cuadro que lo copia y vuelve copiar para intentar comprender el repertorio artístico de los gestos del autor original, claro ejemplo de estética repertorial; otro se aproxima a una obra que representa a una chica en la playa desde las emociones y ensoñaciones que le provoca el cuadro, en una clara reflexión disposicional; finalmente otro personaje está admirado de una escultura masculina por los valores que encarna, mira la obra desde la efectividad, dando juego a la ejemplaridad para cristalizar dichos valores en su vida. Aquí vemos como en un entorno cinematográfico podemos descubrir las diferentes aproximaciones al arte, que desde la estética modal, no se excluirían, sino que tendríamos que dar una visión de todas las posibles dialécticas sin excluirlas y saber que, como explicaba el injustamente olvidado Lupasco, toda realidad artística o cinematográfica "se crea con la contradicción de lo idéntico y lo no idéntico, es decir, con coexistencia de lo homogéneo y lo eterogéneo" (Lupasco 1968. P. 29).

\section{Biliografía}

Alexander, Christopher. 1980. Un lenguaje de patrones, Barcelona: Gustavo Gilli. 
Brecht, Bertolt (1973). El compromiso social en la literatura y el arte. Barcelona: Península.

Claramonte Arrufat, Jordi. 2016. Estética modal, Madrid: Tecnos

- 2015. Desacoplados, Madrid: UNED

Debord, Guy (2008). La sociedad del espectáculo. Valencia: Pre-textos.

Hartmann, Nicolai.1956. Ontología, México: Fondo de Cultura Económica, Vol. I-II-III.

Palazón, Alfonso and Ramé, Jesús. 2018. "El error de Narciso: Alfabetización audiovisual y la educación secundaria" in Avanca Cinama. Internacional conference, Avanca (Portugal): Cine-Clube de Avanca.

Lukács, György. 1967. Estética. Barcelona: Grijalbo

— (1973). Sociología de la literatura. Madrid: Península.

- 2003. "Las tareas de la filosofía marxista en la nueva democracia" in Testamento político y otros textos sobre política y filosofía. Buenos Aires: Ediciones Herramienta

Lupasco, Sthéphane. 1968. Nuevos aspectos del arte y la ciencia, Madrid: Guadarrama.

Pirro, Ugo. 1990. Celuloide, Madrid: Libertarias.

Ramé, Jesús y Jordi Claramonte. 2019. "Glosario" in No lo saben, pero lo hacen, Madrid: Plaza y Valdés.

Tatarkiewicz, Wladyslaw. 2015. Historia de seis ideas. Arte, belleza, forma, creatividad, mímesis, experiencia estética, Madrid: Tecnos.

Valverde, José Enrique. 1998. "1951-1961: Conformismo y disidencia". In VV.AA. Cuadernos de la academia. Historia de cine español, Madrid: Academia de las Ciencias y las Artes Cinematográficas de España.

VV.AA. 1993. Textos y manifiestos del cine, Madrid: Cátedra.

\section{Filmografia}

2019, tras la caída de Nueva York. 1980. Segio Martino. Italia.

Alien: el octavo pasajero. 1979. Ridley Scott. Estados Unidos.

Alien II. Sobre la tierra. 1980. Ciro Ippolito y Biagio Proietti. Italia.

Blade Runner. 1982. Ridley Scott. Estados Unidos.

Centauros del desierto (The Searchers). 1956. John

Ford. Estados Unidos.

Contaminación alíen invade la tierra. 1980. Luigi Cozzi. Italia.

Desafío total. 1990. Paul Verhoeven. Estados Unidos.

El atraco (The maiden Heist). 2009. Peter Hewitt. Estados Unidos.

El hombre lobo. 1941. George Waggner. Estados Unidos.

El hombre lobo. 2010. Joe johston. Estados Unidos.

El ladrón de bicicletas. 1948. Vittorio de Sica. Italia.

Están vivos (They live).1988. John Carpenter.

Ginger Snaps. 2000. John Fawcett. Canada.

Hijos de los hombres. 2006. Alfonso Cuarón. Reino Unido.

Ladrón de bicicletas. 1948. Vittorio de Sica. Italia

Mad max. 1979. Goerge Miller. Estados Unidos.

Matrix. 1999. Lilly y Lana Wachowski. Estados Unidos

Muerte en Venecia. 1971. Luchino Visconti. Italia.

Rebobine, por favor. 2008. Michel Gondry. Estados

Unidos.

Starship Troopers.1997. Paul Verhoeven. Estados

Unidos.

Terminator. 1984. James Cameron. Estados Unidos.

Terminator II. Shoking Dark. 1990. dBruno Mattei. Italia. 